\title{
Estratégias retóricas da publicidade: uma proposta de matriz classificatória ${ }^{1}$
}

\section{Julio Cesar Lemes de Castro}

\section{Resumo}

Propõe-se neste artigo uma matriz para identificar e classificar as estratégias retóricas mais abrangentes utilizadas historicamente pela publicidade. Trata-se de um trabalho de articulação teórica, escorado em pesquisa bibliográfica de alcance interdisciplinar e ilustrado com exemplos retirados da práxis publicitária. Inspirando-se na teoria lacaniana dos discursos, o texto toma a cada um destes seu traço mais característico como alicerce de uma determinada estratégia retórica: a imposição (discurso do senhor), a argumentação (discurso da universidade), a sedução (discurso da histeria) e a cumplicidade (discurso do capitalismo). Tais estratégias variam de acordo com 0 produto, o veículo, o público e a cultura, e combinamse de diversas maneiras. Ao longo do tempo, pode-se constatar, grosso modo, o predomínio sucessivo das várias estratégias.

\section{Palavras-Chave}

Publicidade. Retórica. Discursos.

Julio Cesar Lemes de Castro I julio@jclcastro.com.br Doutor em Comunicação e Semiótica pela Pontifícia Universidade Católica de São Paulo - PUC-SP, Brasil. Pós-doutor em Psicologia Social pela Universidade de São Paulo - USP, Brasil - e em Comunicação e Cultura pela Universidade Federal do Rio de Janeiro UFRJ, Brasil. Pesquisador do Laboratório de Teoria Social, Filosofia e Psicanálise (Latesfip-USP).

\section{Uma matriz retórica \\ para a publicidade}

Este artigo propõe uma matriz para identificar e classificar as estratégias retóricas mais gerais das quais a publicidade se serve no decorrer do tempo.

A inspiração para tanto é a teoria dos discursos de Lacan (1991), em que o termo "discurso" tem um sentido lato, sendo definido como sinônimo de laço social. Cada discurso expressa uma variante distinta de relação de poder, à exceção do discurso do analista, que implica o aplainamento total dessa relação. 0 ponto de partida é o discurso do senhor, uma modalidade de laço social que consiste em uma relação de poder direta, explícita, e é 0 antípoda do discurso do analista. Já 0 discurso da universidade distingue a burocracia, na qual o poder se manifesta de forma camuflada e está associado à persuasão racional. Outro discurso, o da histeria, entretém com a estrutura clínica homônima uma relação de homologia, cujo eixo é a sedução, o desejo de ser desejado pelo outro. Pode-se lobrigar uma similitude entre os discursos e os tipos de dominação de Weber, em 
que pese estes não constarem entre as referências lacanianas: 0 discurso do senhor equivaleria ao tipo tradicional; 0 discurso da universidade, ao burocrático; o discurso da histeria, ao carismático. Apresentado posteriormente por Lacan (1978), o discurso do capitalismo - que não concerne ao capitalismo como um todo, mas a sua etapa tardia - fundamenta-se no imperativo do gozo, diante do qual todos são proletários e mantêm entre si uma relação de cumplicidade.

Na senda do esquema lacaniano, que admite diferentes aplicações no campo da comunicação (Castro, 2016), não se considera aqui o discurso publicitário somente em termos formais, como uma construção de linguagem, mas como 0 laço que se estabelece entre o publicitário e 0 consumidor, o qual envolve uma relação de poder. Isso vai ao encontro de algo evidenciado pela antropologia do consumo, a atribuição de sentido aos bens materiais como um processo social que se apoia no poder. "Em última instância, o consumo tem a ver com o poder", declaram Douglas e Isherwood (1996, p. 63). "Política (no sentido amplo de relações, suposições e disputas relativas ao poder) é o que liga valor e troca na vida social das mercadorias", sustenta Appadurai (1986, p. 57, grifo no original). É uma relação à qual não se pode evadir, em uma cultura em que a publicidade está disseminada por toda parte e parece integrar-se naturalmente ao ambiente. Nessa relação, a iniciativa cabe ao publicitário, que se empenha em influir na mentalidade e no comportamento do consumidor, não obstante este não ter um papel passivo. Isso acontece de diversas maneiras, que correspondem a variantes de laço social enquanto estratégias retóricas.

0 traço mais característico de cada discurso pode ser tomado como alicerce de cada uma das estratégias retóricas básicas utilizadas pela publicidade: a imposição (discurso do senhor), a argumentação (discurso da universidade), a sedução (discurso da histeria) e a cumplicidade (discurso do capitalismo). Fica excluído dessa série de paralelismos o discurso do analista, cuja dinâmica é bastante distante daquela vigente no mundo da publicidade. É verdade que seria perfeitamente exequível aplicar mais estritamente a teoria dos discursos à retórica publicitária, considerando os elementos e lugares de cada discurso e os algoritmos em que eles se organizam, conforme as formulações lacanianas, mas esse detalhamento teria mais interesse para a pesquisa em psicanálise do que para a pesquisa em publicidade. Por isso, a opção adotada foi utilizar essa teoria como fonte de inspiração, sem, entretanto, embrenhar-se em seus detalhes.

Para 0 intento deste artigo, não há mister tampouco de entrar em pormenores da práxis publicitária, mas de apreender o cerne de cada posicionamento, daí, em vez de "retórica", a preferência por "estratégia retórica", o termo "estratégia" sendo utilizado no sentido mais geral descrito por Foucault (2001, p. 1060, grifo no original), "para designar a escolha dos meios empregados para 
chegar a um fim; trata-se da racionalidade posta em prática para atingir um objetivo".

Devem ser levadas em conta variações das estratégias retóricas da publicidade devido a diversos fatores, visto que algumas podem ser mais apropriadas do que outras a um determinado produto, veículo, público e cultura. Além disso, como os "tipos ideais" de dominação em Weber (1922, p. 124), sobre os quais se pode dizer que "nenhum dos três [...] sói aparecer em forma histórica realmente 'pura'", os discursos em Lacan combinam-se entre si, todos eles podendo estar presentes em uma dada situação; de modo análogo, as estratégias mais abrangentes da publicidade articulam-se entre si de várias maneiras. Uma matriz classificatória desse jaez tem a vantagem de ser flexível, uma vez que um anúncio pode aliar facetas de diferentes estratégias, embora nem sempre seja factível localizar claramente nela um anúncio específico. Cabe assinalar ainda que a matriz ora proposta é um ângulo concebível de análise da retórica da publicidade, o qual não exclui outros nem pretende substituí-los.

\section{A estratégia da imposição}

A estratégia retórica da imposição, a mais rudimentar de todas, consiste, via de regra, em mostrar alguém que profere uma sentença imperativa a partir de uma condição de autoridade. Quanto à mensagem, trata-se de algo simples, do tipo "Compre isso!"
Essa estratégia enforma a indústria nascente da publicidade, seja em função do desenvolvimento incipiente desta, seja em função da conjuntura histórica. Quando o consumo, no término do século XIX, começa a assumir uma dimensão massiva, a comunicação com os consumidores tende a seguir as diretrizes que caracterizam a comunicação política ou religiosa. Na medida em que, nessas, as pessoas estão acostumadas a receber orientações de uma figura centralizadora, é natural que o mesmo ocorra na publicidade. Por outro lado, a visão disciplinar dos industriais transborda para o consumo; em 1913, por exemplo, Henry Ford cria um Departamento Sociológico, composto de investigadores que fazem visitassurpresa à residência de cada empregado e supervisionam seus hábitos como consumidor. E, assim como Ford e Taylor preocupam-se com os aspectos fisiológicos e psicológicos do rendimento do trabalhador, a publicidade nessa fase, para lidar com o consumidor, recorre a observações da psicologia experimental com relação à atenção e a estímulos.

A fim de salientar a mensagem, 0 anúncio pode fazer uso de impactos visuais, como fontes pesadas, tipos grandes, letras maiúsculas, pontos de exclamação ou cores brilhantes. Para mensagens transmitidas por rádio e televisão, recursos equivalentes são o tom enfático e 0 volume tão alto quanto possível. Como observa Dichter (2002, p. 144), "muitos anunciantes, dirigentes públicos, pessoas encarregadas de atingir um determinado objetivo sentem também 
muitas vezes que, para isso, é suficiente colocar um ponto de exclamação no final dele e usálo como um lembrete". Ademais, iterações são empregadas para reforçar o que é dito, como um partidário norte-americano desse gênero de publicidade defende no início do século XX:

Psicologicamente, a repetição é um dos métodos mais eficazes de convencimento. 0 bom e velho ditado é tão adequado que não posso evitar repeti-lo: "Água mole em pedra dura tanto bate até que fura". Assim, 0 apelo constante, persistente e consistente à atenção mental do possível cliente eventualmente leva à abertura da porta, e então 0 resto é fácil (Lewis, 1908, p. 281).

A interpelação direta do público coaduna-se com a estratégia impositiva: "Alguns redatores foram capazes de obter atenção e bons resultados através de um estilo vigoroso de texto dirigido ao leitor como se fosse uma carta, no qual o pronome 'você' foi livremente usado. Era 'Você, sr. Leitor', 'Você precisa disso', e assim por diante" (Hall, 1915, p. 114-115). Outra possibilidade é dirigir-se visualmente ao destinatário, como um pôster da companhia Godfrey Phillips \& Sons, de Londres, por volta de 1910, que traz um homem junto a um maço de cigarros dessa companhia, com o dedo indicador assestado para quem vê.

0 enfoque coercivo dessas interpelações encontra terreno bastante favorável na propaganda política. Podemos pensar no pôster de recrutamento norteamericano, concebido por James Montgomery Flagg em 1917, que exibe a pose de autoridade do Tio Sam apontando firmemente com o indicador para 0 espectador, secundada pela frase "Eu quero VOCÊ para o exército dos EUA". 0 precursor desse cartaz é o da campanha de alistamento do exército britânico, em 1914, representando Lord Kitchener, o secretário de Estado britânico para a guerra, com pose idêntica e as palavras "QUER VOCÊ". Peças propagandísticas similares aparecem na Alemanha, na União Soviética e em outros países (GINZBURG, 2001). Há algo de superegoico no jeito como essas figuras interpelam os jovens que constituem seu alvo, incitando-os a pôr-se em movimento - o que significa, na prática, não somente se dirigir a um posto para alistar-se, mas também se engajar no esforço bélico. Bernays (1928, p. 19), que participa da propaganda de guerra estadunidense, arrazoa mais tarde: "A minoria descobriu uma ajuda poderosa para influenciar maiorias. Verificouse ser possível moldar de tal forma a mente das massas que elas vão lançar sua força recémadquirida na direção desejada".

Com o tempo, o poder persuasivo da publicidade exige maiores doses de habilidade e sutileza, em um quadro de competição mais acirrada e público mais maduro. Perante a cacofonia de mensagens, tentar captar a atenção por ser mais ruidoso não é 0 caminho mais astuto. Vale notar, a propósito, que as pesquisas de Lazarsfeld e seus colegas (Lazarsfeld; Berelson; Gaudet, 1944) relativizam a crença no poder da mídia, questionando a metáfora teórica da agulha hipodérmica, segundo a qual o conteúdo dos meios de comunicação de massas seria injetado diretamente na mente do 
público. Mas, apesar de o estilo impositivo ter-se tornado menos corriqueiro, ele sobrevive em certas circunstâncias e em combinação com outros.

Pode-se supor que um tom contundente é mais conveniente para dirigir-se a um público mais jovem ou menos instruído, ou a uma multidão tomada em conjunto, que, presumivelmente, seriam mais tolerantes quanto ao excesso de estímulos envolvidos. Um raciocínio semelhante é aplicável à promoção de produtos em liquidação, quando a ênfase parece mais justificável e 0 formato possivelmente incômodo da mensagem é compensado pelas vantagens anunciadas.

Para Rosser Reeves (1961, p. 39), o consumidor tem uma espécie de caixa na mente, com capacidade limitada, para guardar os anúncios de cada classe de produto, de sorte que uns disputam espaço com outros. Além disso, ele tende a lembrar-se de uma só informação de cada anúncio (ibid., p. 34). Nas décadas de 1940 e 1950, Reeves, presidente da agência Ted Bates, com sede em Nova York, põe em circulação um influente conceito de marketing que ele denomina "unique selling proposition" (USP), ou "proposição única de venda": um apelo poderoso, único entre os concorrentes e facilmente transmissível, é investido em um produto e passa então a ser repetido continuamente. Esse é o caso dos comerciais de TV, que vão ao ar em 1956, para 0 analgésico Anacin, martelando o slogan "Rápido, rápido, rápido alívio!”. A despeito de serem irritantes para muitos, seu impacto nas vendas é

indubitavelmente positivo.

0 infomercial, que em sua versão atual surge no início dos anos 1980, bombardeia o espectador com uma apresentação entusiasmada e uma exaltação das qualidades do produto mediante descrições e depoimentos. Em infomerciais de formato longo, com pelo menos 15 minutos de duração, o conteúdo é repetido várias vezes, com 0 fito de atingir a audiência que flutua entre os canais e de reforçar a impressão naqueles que permanecem sintonizados. 0 espectador é induzido a comprar por impulso, por exemplo, com promessas de brindes para os primeiros a telefonarem, ou para aqueles que entrarem em contato durante um determinado intervalo.

Conquanto, no decurso do tempo, decline 0 recurso à retórica impositiva, algo desta faz parte da própria natureza da práxis publicitária. Para Adorno (2003, p. 338), o espírito insuflado na cultura de massa em geral é "a voz de seu senhor". E pode-se dizer que a propaganda, especificamente, tem um quê tirânico intrínseco, na medida em que tenta capturar alguém por todos os meios, incluindo sentimentos e ideias, conscientes e inconscientes, como assevera em chave hiperbólica Ellul (1990, p. 22): "Pelo mito que ela cria, a propaganda impõe uma visão global, de conhecimento intuitivo, que só é passível de uma interpretação única, de apenas um lado, e que exclui qualquer divergência”. A retórica impositiva trai um desejo de assujeitamento do 
consumidor pelo publicitário, que nas demais estratégias, representando modalidades mais sutis de convencimento, queda disfarçado.

\section{A estratégia da argumentação}

Através da estratégia da argumentação, buscase incutir na publicidade um teor supostamente técnico, informativo.

Vale considerar que o consumo de massa, cuja explosão é coetânea do taylorismo e do fordismo, não é afetado somente pelo viés impositivo do dispositivo disciplinar, mas também por seus parâmetros de racionalização. Assim, Lillian Gilbreth, viúva de um dos nomes proeminentes da chamada "administração científica", faz toda uma carreira propondo a racionalização do lar apoiada em bens de consumo (Graham, 1999). É natural que a publicidade igualmente lance mão da racionalidade, pelo menos aparente, tentando convencer o consumidor mediante argumentos sensatos, dados minuciosos e jargão especializado. Em uma perspectiva formal, isso envolve priorizar a linguagem verbal, mais útil para essa tarefa do que as imagens.

0 eixo da indústria nascente da publicidade, nos Estados Unidos, são os medicamentos com fórmulas proprietárias e sem resultados comprovados, vendidos ao público diretamente, sem receita ("patent medicines"). Não estando sujeitos a nenhuma espécie de regulação, e contendo frequentemente drogas como álcool e opiácios, eles prometem a cura de uma profusão de problemas de saúde. Produtos como a CocaCola começam dessa forma (Pendergrast, 2013). Esses produtos dependem, sobretudo, de divulgação para terem sucesso, e impulsionam a introdução de técnicas especialmente para anunciá-los. Por outro lado, operando habitualmente com vultosas margens de lucro, os recursos de que dispõem para divulgação são abundantes. Se bem que não funcionem consoante as alegações, a propaganda deles segue uma linha de raciocínio pragmático, pormenorizando os hipotéticos benefícios e aduzindo testemunhos, inclusive de profissionais da saúde.

Com efeito, à semelhança da estratégia da imposição, na estratégia argumentativa se pode recorrer a uma figura de autoridade, mas neste caso a autoridade deriva da expertise presumida dessa figura. Geralmente, é um especialista que tem alguma relação com o produto em questão e no qual, em tese, se poderia confiar para emitir uma boa avaliação dele, como um dentista em uniforme branco louvando os méritos de um creme dental. 0 que realmente importa, de qualquer modo, é a aparência de competência técnica e veracidade. Nas primeiras décadas do século passado, os médicos tornam-se uma constante em campanhas relacionadas à alimentação, à higiene e, obviamente, a remédios. A melhor maneira de persuadir as pessoas a comer bacon, argumenta Bernays (1928, p. 53-54), é conseguir que médicos recomendem isso ao público, pois o publicitário "sabe, como uma certeza matemática, que um grande número de pessoas 
irá seguir o conselho de seus médicos, porque ele entende a relação psicológica da dependência dos homens em relação a seus médicos".

Com a evolução da práxis publicitária, a estratégia da argumentação fica mais refinada. 0 primeiro princípio enunciado por David Ogilvy no anúncio "Como criar publicidade que vende", elaborado para promover sua própria agência, Ogilvy \& Mather, estipula que "o efeito de sua publicidade em suas vendas depende mais desta decisão que de qualquer outra: como você deve posicionar seu produto?”. Ele aplica esse princípio na campanha para 0 sabonete Dove, nos anos 1950, que 0 distingue dos concorrentes com o pretexto de que "só Dove é um quarto de creme hidratante". Essa campanha, que auxilia o sabonete a transformar-se no mais vendido nos Estados Unidos, é uma excelente amostra de como explorar as propriedades do produto como vantagens.

Mas, como comenta Barthes (1970, p. 78, grifo no original) em Mitologias, o saldo do pretenso recurso à razão pela publicidade é comumente incompreensível - "um vocabulário molieresco complicado quando muito com uma ponta de cientificismo (o agente bactericida $R$ 51)". Embora 0 anúncio, aparentemente, nos convide a refletir, a calcular, a ser razoável, ele não espera que façamos efetivamente isso, posto que dita racionalidade não passa de artifício.

Selecionar alguma das características do produto como chamariz de vendas pressupõe familiarizarse ao máximo com essas características, como aconselha Ogilvy (1985, p. 11): "Primeiro, estude o produto que você vai anunciar. Quanto mais você souber sobre ele, mais provável será que você descubra uma grande ideia para vendê-lo". Além disso, a publicidade procura entender o público em seus aspectos psicológicos e sociológicos, segue uma série de convenções técnicas quanto à forma e ao conteúdo dos anúncios e mensura seus resultados, o que the confere uma aparência de seriedade científica. Mesmo a utilidade das máquinas para monitorar variáveis associadas ao consumo é apontada antes do advento dos computadores:

A técnica mais desenvolvida para medir 0 comportamento de compra é aquela possibilitada pela triagem elétrica e pelas máquinas de tabulação. Esses dispositivos engenhosos tornaram viável registrar e classificar 0 comportamento do público consumidor, bem como o comportamento dos que servem a esse público, em uma escala até então impraticável (Link, 1932, p. 248).

Assim, ainda que a retórica de um anúncio não se fie diretamente em argumentos racionais, a racionalidade está usualmente embutida em seu background. Até os anos 1950, contudo, as pesquisas quantitativas privilegiam uma correlação genérica do comportamento do consumidor com a categoria socioeconômica à qual ele pertence, 0 que favorece práticas mercadológicas padronizadas típicas do consumo de massa.

\section{A estratégia da sedução}

Na publicidade, a estratégia da sedução consiste em construir, ao redor de um produto, uma 
fantasia apta a cativar o desejo do consumidor. Livre curso é concedido à imaginação, de sorte que uma vasta gama de cenários, envolvendo glamour, romantismo, aventura, exotismo e similares, pode ser agregada às mercadorias. Nessa operação, a imagem tende a ganhar relevância em relação ao texto. Uma autoridade também está presente, na figura velada do anunciante ou de seus avatares no interior do anúncio, os quais ensinam o consumidor como e o que desejar.

0 fundamento dessa estratégia é sugerido por Lippmann (1927, p. 37-38), para quem o êxito de qualquer tentativa de influenciar as massas repousa sobre a habilidade em manipular "símbolos que reúnem emoções depois de estas terem sido destacadas de suas ideias". Na medida em que os sentimentos são menos específicos e mais poderosos do que as ideias, quem os mobiliza "é capaz de forjar uma vontade homogênea a partir de uma massa heterogênea de desejos". 0 processo é, portanto, o equivalente de "uma intensificação do sentimento e uma degradação de significância”. Em diapasão semelhante, Dichter (2002, p. 16) constata que, "quando 0 vendedor pára de vender e nos diz para escolher racionalmente, nos sentimos abandonados e francamente insultados por sua indiferença", e pondera que "a publicidade moderna se tornou cada vez mais consciente da importância das emoções humanas" (ibid., 2002, p. 275).

A função de sedução aparece na exposição feita por Benjamin (1991) acerca da fantasmagoria do consumo no século XIX, o contexto mágico para a mercadoria provido então por galerias, lojas de departamento e feiras internacionais em Paris, que a propaganda ulteriormente retoma. Sob o modelo fordista, embora o consumo seja impregnado, como vimos, de aspectos disciplinares, ele funciona adicionalmente como válvula de escape: a expectativa é que o mesmo sujeito tenha uma postura ascética nas horas de trabalho e hedonista nos momentos livres (Bell, 1978, p. 71-72). Com isso, a retórica da sedução acaba tornando-se a mais representativa da publicidade. 0 triunfo dessa estratégia vis-à-vis a da argumentação é demonstrado pelo cotejo histórico entre as campanhas de promoção de automóveis:

Os anúncios pré-Primeira Guerra Mundial eram quase todos baseados na simples apresentação de detalhes técnicos. Já nos anos 1920 eram praticamente desprovidos de informações; em vez disso, prometiam estilo, status, ou fugir para uma "vida real" exótica longe de experiência comum do leitor (Lears, 1983, p. 27).

Típica da retórica da sedução é a série de anúncios anuais da Coca-Cola para o Natal com o Papai Noel desenhado por Haddon Sundblom, do início dos anos 1930 em diante. Tais anúncios concorrem para impulsionar suas vendas no inverno e têm forte repercussão junto às crianças. Apesar do mito difundido a esse respeito, não é fato que os anúncios da Coca-Cola sejam responsáveis pela imagem moderna de Papai Noel, com roupa e capuz vermelhos, barba e bigode brancos, mas, de todo modo, eles contribuem para consolidá-la. Outro exemplo pregnante dessa 
retórica é o Homem de Marlboro, um caubói de aparência viril cavalgando no campo, idealizado por Leo Burnett em 1954. Em uma época em que os cigarros com filtros, e este em particular, têm uma imagem feminina, tal personagem converte a marca em um emblema de masculinidade.

Encarnado por vários atores, o Homem de Marlboro comparece por décadas na publicidade do produto e conquista uma forte presença na cultura popular. É fácil perceber nesses casos que, em contraste com o que ocorre na estratégia argumentativa, os anúncios realçam atributos que não têm relação direta com o produto, mas são acoplados artificialmente a eles pela fantasia.

A dissociação entre emoções e ideias mencionada anteriormente, com as primeiras destinando-se a ser retidas, remete-nos ao conceito psicanalítico de repressão (Verdrängung). Esta se aplica especialmente às condições de produção da mercadoria. Barthes (1970, p. 140-141) observa como "0 novo Citroën cai manifestamente do céu", comemora "uma ausência de origem", designa "0 limiar de uma nova fenomenologia da montagem, como se progredíssemos de um mundo de elementos soldados a um mundo de elementos justapostos e que se mantêm unidos apenas em virtude de sua forma maravilhosa".

Por certo, o concurso da psicanálise, que durante um período desempenha um papel conspícuo na publicidade, revela-se valioso para a estratégia da sedução. 0 pioneiro neste caminho é Edward Bernays, sobrinho de Freud, que recebe o epíteto de "pai de relações públicas". Em Propaganda, Bernays (1928, p. 52) escreve:

Esse princípio geral, segundo o qual os homens são, em grande parte, impulsionados por motivos que eles escondem de si mesmos é tão verdadeiro na psicologia de massa como na psicologia individual. É evidente que o propagandista de sucesso deve compreender os verdadeiros motivos e não se contentar em aceitar as razões que os homens dão para o que eles fazem.

Tal princípio orienta as ações do próprio

Bernays. Um de seus trabalhos mais famosos, encomendado pela American Tobacco Company, visa estimular 0 vício de fumar entre as mulheres. Ele propõe a equipolência entre cigarro e pênis e esteia sua estratégia na premissa de que 0 ato de fumar, então praticado por mulheres tidas como vulgares, deve ser conectado à emancipação feminina, como um meio de as mulheres conquistarem seu pênis. Com esse intuito, ele prepara um evento por ocasião da Easter Parade em Nova York, em 1929, no qual vinte modelos elegantemente vestidas acendem cigarros e empunham cartazes rotulando-os como "tochas de liberdade".

Outro profissional notável é Ernest Dichter, psicanalista vienense que se estabelece nos EUA e passa a fornecer consultoria para agências de publicidade. Para investigar os catalisadores inconscientes do comportamento do consumidor, Dichter inventa a pesquisa motivacional, usando procedimentos emprestados à psicanálise, como a entrevista profunda, calcada na livre associação. Como ele explica: 
Se investigarmos com suficiente profundidade, descobriremos que 0 que as pessoas querem mesmo não é apenas produtos mais práticos e valores materialistas. Muito poucos produtos têm aspectos puramente utilitários. Eles são realmente comprados só porque nos ajudam a alcançar uma série de metas psicológicas mais profundas (Dichter, 2002, p. 259).

0stentando o crédito de vários empreendimentos bem-sucedidos, que incluem a campanha "Coloque um tigre no seu tanque", para a Esso, e o conceito da boneca Barbie, para a Mattel, seu nome granjeia projeção. No entanto, tanto Bernays como Dichter acabam sendo alvos de severo escrutínio. 0 primeiro, devido a compromissos controversos, como seu trabalho para a indústria do tabaco e seu papel em um golpe militar da Guatemala a serviço da United Fruit. 0 segundo, por conta do estatuto que ele ganha como um "persuasor oculto" (Packard, 2007) e do apoio que, na prática, confere ao culto da domesticidade feminina após a Segunda Guerra Mundial (Friedan, 1963). Mais do que isso, com 0 tempo táticas de publicidade hauridas diretamente da psicanálise se tornam mais conhecidas do público e, por conseguinte, menos eficazes.

De certa maneira, podemos dizer que a retórica da sedução tende a incorporar as da imposição e da argumentação. 0 fato de uma campanha reiterar um slogan pegajoso ou socorrer-se do discurso competente de um médico não impede que seu fulcro seja a sedução, não a imposição ou a argumentação. Como nas feiras internacionais do século XIX que atraem a atenção de Benjamin, até a tecnologia não aparece como um componente racional, mas é incorporada ao espetáculo. Frank (1997, p. 48) relata 0

\begin{abstract}
uso frequente pelos publicitários dos anos 1950 da terminologia da Guerra Fria e das descrições emprestadas dos militares da era dos jatos: aqui um carro é colocado ao lado de um avião de combate, lá uma empresa química usa representações de equipamento militar para atrair a boa vontade do público.
\end{abstract}

Todavia, precisamente porque a estratégia da sedução se dissemina tanto, ela sujeita-se a desembocar em clichês e, com isso, a desgastarse. Esse é um dos fatores que contribuem para uma transformação capital na publicidade, com a emergência de uma nova estratégia.

\section{A estratégia da cumplicidade}

A retórica que predomina na publicidade das últimas décadas procura instaurar uma cumplicidade com o consumidor. Este é tratado como alguém que sabe das coisas, é inteligente e tem personalidade, ou seja, como alguém que não se prestaria a ser persuadido racionalmente ou seduzido, e menos ainda a tolerar alguma imposição. 0 que se oferece a ele é 0 reconhecimento de sua singularidade, evidenciado, acima de tudo, por essa diferença de abordagem.

Em oposição à retórica impositiva, mas contrastando, ademais, com as da argumentação e da sedução, a retórica da cumplicidade é mais sutil. Muitas vezes, o anúncio não enaltece diretamente 0 produto, mas investe na criação 
de um clima em torno dele ou da marca. Há circunstâncias, como na publicidade de grifes de moda sofisticadas, em que 0 produto e mesmo a marca são mostrados discretamente, como se fosse uma propaganda institucional. A ideia é que 0 essencial é gerar uma sintonia em um nível mais amplo com o consumidor, conjecturado como alguém com capital cultural suficiente para completar 0 sentido do que lhe é exposto. A venda seria uma consequência da identificação assim estabelecida.

A diferença de premissa dessa estratégia em relação às demais pode ser formulada em termos de distância temporal e espacial. Quando um anúncio conclama "Venha para o mundo de Marlboro", é como se o consumidor precisasse ser levado de alguma forma a integrar no futuro um mundo do qual ele ainda não faz parte. Já na retórica da cumplicidade, o reconhecimento concedido ao destinatário do anúncio não se limita à sagacidade da abordagem, mas se estende à sugestão das virtudes em comum que já existiriam entre ele e 0 produto. Não se trata de convencê-lo sobre o produto, mas de conduzir as coisas para que ele próprio corrobore essa afinidade tácita. 0 intervalo temporal é curto-circuitado: ele é reputado como virtual consumidor de alguma coisa antes de sê-lo de fato. 0 intervalo espacial é dissolvido: não é preciso levá-lo para o mundo do anunciante, mas de fazer com que ele descubra/transforme seu próprio mundo, como sugerem campanhas como "Abra seu mundo" (Heineken, 2011),
"Mobilizando seu mundo" (AT\&T, 2014) ou

"Atualize seu mundo" (Microsoft, 2015).

Quando o publicitário se exprime como se entre ele e 0 consumidor não houvesse uma relação de poder, ou quando o tom do anúncio insinua que ele não está engajado em induzir o consumidor a comprar, afinal de contas, ambos sabem que isso não é verdade. Na estratégia da cumplicidade, em lugar da repressão (Verdrängung), característica da histeria e subjacente à sedução, avulta 0 desmentido (Verleugnung), característico da perversão e próximo, em um registro filosófico, do cinismo (Castro, 2014). A fórmula do desmentido é enunciada por Octave Mannoni (1969, p. 9-33): "Je sais bien, mais quand même..." ("Eu sei muito bem, mas mesmo assim...”). Em outras palavras, malgrado a percepção contrariar a crença, esta última continua a ser sustentada.

Cumpre assinalar que há também um elemento de desmentido nas estratégias retóricas mais convencionais. Muito do que a publicidade sugere como excepcional a propósito de um produto, salientando dados a seu respeito (na estratégia da argumentação) ou acoplando a ele uma fantasia (na estratégia da sedução), não passa de mera sugestão. No fundo, o consumidor tem consciência de que 0 ingrediente mirabolante anunciado no comercial de sabão em pó pouco discrepa de substâncias encontradas em produtos similares, e de que não há nenhum elo necessário entre uma bebida e 0 ambiente requintado em que ela é consumida na propaganda. Porém, quando essas 
estratégias são bem-sucedidas, ele deixa-se iludir pelas sugestões que lhe são ofertadas, tomando-as como algo efetivo. De todo modo, na retórica da cumplicidade 0 distanciamento das convenções aumenta a dependência em relação a esse mecanismo, porquanto a franqueza ostensiva e 0 aspecto menos manipulativo encobrem a relação de poder na publicidade. Ou seja, à proporção que, por um lado, a crença na inexistência dessa relação de poder é incentivada, por outro, 0 desmentido dessa crença pela percepção de que essa relação está efetivamente presente assume caráter mais pronunciado.

Ilustrações paradigmáticas da estratégia da cumplicidade são as campanhas para a Volkswagen desenvolvidas pela agência Doyle Dane Bernbach (DDB), as quais deslancham o que ficou conhecido na Madison Avenue como a "revolução criativa" da publicidade, a partir do fim dos anos 1950. Em uma quadra em que os fabricantes disputam entre si quem produz os automóveis maiores, mais exuberantes, que melhor corporificam a cultura norte-americana, o Fusca salta à vista por ser pequeno e feioso, além de estar imbuído da imagem de veículo de massa projetado na Alemanha nazista. Em face do desafio, a publicidade admite candidamente suas limitações e, simultaneamente, 0 erige em carro cult, para pessoas que não se deixam impressionar pela aparência e sobressaem em meio à massa. A tática de proclamada humildade é retomada em uma campanha que essa mesma agência faz para a Avis em 1966. Ressaltando a posição de vice-liderança dessa locadora em seu segmento, motivação alegada para que ela se dedique sempre mais, a campanha não perde a oportunidade de confrontar sua honestidade inusual com as promessas bombásticas da maioria dos anúncios. É como se 0 publicitário quisesse, de fato, dizer: "Nós sabemos que não é mais possível enganá-lo da forma habitual, por isso não vamos mais jogar esse jogo".

Na verdade, brincadeiras cúmplices entre 0 publicitário e o público não são exatamente algo novo: no século XIX, P. T. Barnum é bem-sucedido com seus audaciosos golpes de marketing, mas seus exageros não escapam aos espectadores e são encarados como integrantes do show. Que limitações por parte do anunciante contem a seu favor tampouco é novidade: Dichter (2002, p. 57-58) nota que um discurso ou depoimento com a intenção de vender algo se torna mais crível caso seu autor cometa algum erro aqui e ali, pois isso o reveste de uma dose de humanidade. A cumplicidade com a audiência, de qualquer maneira, galga outro patamar a partir da "revolução criativa". 0 humor que chega ao ponto da autodepreciação, nos anúncios do Fusca e da Avis, pressupõe no público a aptidão para entender a ironia e entrar no jogo proposto pelo publicitário. Também está prevista nesse tipo de jogo a desmistificação da retórica publicitária convencional. Assim, a campanha do refrigerante Sprite, nos anos 1990, graceja com a prática de construção de imagem das mercadorias através do slogan: "Imagem não é nada. Sede é tudo. Obedeça a sua sede". 
Outra forma de cumplicidade com o público é pela via da polêmica. Na década de 1980, a marca italiana Benetton lança uma sucessão de campanhas, compostas basicamente de fotografias bastante controversas de Oliviero Toscani ladeadas pelo logotipo da empresa (contendo os dizeres "United Colors of Benetton") à guisa de legenda, que funcionam como anúncios institucionais. 0 público-alvo é aquele capaz de compartilhar a ousadia do anunciante.

A rebeldia dos que se situam à margem das convenções pode operar igualmente como móbil de cumplicidade entre a marca e seus consumidores. Nos anos 1990, a campanha "Pense diferente", com ícones como Albert Einstein, Bob Dylan, Martin Luther King Jr., John Lennon, Muhammad Ali, Mahatma Gandhi e Pablo Picasso, de certo modo coloca os consumidores da Apple em pé de igualdade com tais personalidades. Isso ecoa uma asserção de Steve Jobs, fundador e CEO da Apple, em uma entrevista em 1994, que consta do documentário Steve Jobs: visionary entrepreneur (dirigido por Sally McBurney, 2013): "A vida pode ser muito mais ampla depois que você descobre um fato simples, que é: tudo a seu redor que você chama de vida é composto por pessoas que não eram mais espertas do que você".

As diferentes modalidades que assume a retórica da cumplicidade desenvolvem-se principalmente em torno da marca, que adquire importância crescente nas estratégias de marketing nas últimas décadas. Se antes as marcas eram um meio de dar um traço distintivo aos produtos de uma corporação, elas passam a conotar estilos de vida com os quais é possível o consumidor se identificar (Klein, 2010). A cumplicidade com o consumidor é institucionalizada por intermédio da Gestão de Relacionamento com o Cliente, nome em português para Customer Relationship Management (CRM). Ela consiste em um conjunto de técnicas de marketing para manter e otimizar o relacionamento com os clientes existentes, recompensando sua lealdade, algo que, em princípio, é mais lucrativo para as empresas do que a atração de novos clientes. Exemplos de CRM são os programas de milhagem das companhias aéreas e de benefícios para clientes top dos bancos.

Se as outras estratégias se relacionam de algum modo com a sociedade disciplinar foucaultiana, a estratégia da cumplicidade tem maior afinidade com a sociedade de controle, associada diretamente ao manejo de dados. Este, a partir dos anos 1960, é facilitado e torna-se mais sofisticado com o uso de computadores e, subsequentemente, da internet. Se até então normalmente as pesquisas quantitativas eram genéricas (como a distribuição do consumidor em categorias socioeconômicas) e as pesquisas qualitativas eram individualizadas (como a pesquisa motivacional), as pesquisas psicográficas assentam-se, de certa forma, entre esses dois tipos, procurando mensurar segmentos de mercado ligados a atividades, interesses e opiniões. No limite, 
inclusive o indivíduo é fragmentado, seus dados sendo reagrupados em diferentes compósitos: na sociedade de controle, afirma Deleuze (2003, p. 244), "os indivíduos tornaram-se 'divíduos', e as massas, amostras, dados, mercados ou bancos". Preferências específicas, bem como mudanças de preferências tornam-se detectáveis a partir do mapeamento de tendências; assim, a "inteligência coletiva" extraída da massa de dados de todos os usuários recomendanos os produtos em um site de comércio eletrônico com base em nossas aquisições anteriores, e, especialmente, das mais recentes. A maior detectabilidade do comportamento do consumidor favorece a interação e a cumplicidade com ele.

A hipertrofia dos dados na sociedade de controle toma 0 lugar antes reservado à autoridade; na frase de Pech (2007, p. 126), "as pesquisas ajudam [...] as sociedades sem Deus a tornarem mais suportável o mistério de sua própria identidade". Analogamente, a cumplicidade com o consumidor implica que, no cotejo com outras estratégias, a autoridade seja menos palpável. 0 uso de celebridades e outras figuras modifica-se: se a publicidade no passado incentivava o consumidor a mirar-se em um determinado modelo e a comportar-se como ele, agora o objetivo é que 0 consumidor encontre no modelo atributos melhorados de si mesmo (Salecl, 2004, p. 57), como na campanha "Pense diferente" da Apple, mencionada anteriormente.
0 declínio da autoridade vem junto com 0 declínio da instância repressiva em geral, que é acompanhado da valorização do gozo (termo psicanalítico que designa algo além do prazer, incorporando mesmo um elemento de desprazer). Se a retórica da sedução funda-se na falta e no desejo dela decorrente, na retórica da cumplicidade o papel do gozo é capital. 0 caso da propaganda de sabão em pó é bastante ilustrativo. Anúncios do passado tiravam proveito da insegurança da dona de casa, comparando a brancura da camisa do marido ou do filho com a das roupas de seus colegas. Isso ressaltava uma falta, seja pela desvantagem na comparação, seja porque 0 ato em si de comparar era indício de uma busca de validação. Já os anúncios atuais costumam mostrar uma criança divertindo-se na lama ou com tinta, com a mensagem de que não há nenhum problema, de que o sabão irá limpar tudo. Em lugar da ansiedade com a falta, celebra-se um gozo sem peias. Há uma cumplicidade entre consumidor e publicitário em torno do gozo com o qual o segundo acena para o primeiro, mas há também, simetricamente, um gozo extraído da cumplicidade - um apelo de vendas menos direto significa maior liberdade de criação e maior possibilidade de que a própria publicidade se torne fonte de gozo.

Se outrora a falta era cultivada atribuindo-se peso aos outros (o consumidor era encorajado a contrapor o que ele possuía ou não a seus semelhantes), quando o eixo se desloca para 0 gozo, que tem algo de autista, a relevância dos outros é relativizada. 0 "consumo conspícuo" 
(Veblen, 1918) e a tentativa de "keep up with the Joneses" (expressão surgida a partir de uma tira em quadrinhos norte-americana, na qual uma família se esforça para acompanhar os padrões de consumo de seus vizinhos de sobrenome Jones) perdem sentido em uma era de recuo do consumo de massa. Isso é ainda mais patente nos setores em que o consumo é naturalmente mais personalizado, como a indústria da moda, objeto de um estilo de publicidade que, amiúde, brinca com a transgressão, exibindo, por exemplo, sugestões de comportamentos sexuais fora da norma. No limite, são as transgressões de publicidade contemporânea que constituem a norma, pois não há identidade fixa e todos são convidados a ter seu próprio estilo. Os outros, a bem da verdade, continuam a ter importância, mas como referência negativa: 0 ideal não é imitá-los, mas diferenciar-se deles; ser mais realizado e feliz que eles, mas de um modo singular. A retórica da cumplicidade, entronizando seu alvo em uma posição especial, colabora nessa tarefa.

\section{Evolução histórica da retórica publicitária}

A publicidade evolve de maneira significativa no transcorrer dos anos. Em nossa experiência, testemunhamos isso: por vezes, quando nos deparamos com anúncios antigos, eles provocam em nós uma sensação de estranheza. Podese supor que impressão similar causariam anúncios hodiernos no público do passado. Por isso, desde o final do século XIX os artefatos culturais fornecidos pela publicidade estão entre os mais adequados para representar o Zeitgeist. Uma matéria na Harper's Weekly (The New Advertising, 1897, p. 744) qualifica a publicidade como "um verdadeiro espelho da vida, uma espécie de história fóssil a partir do qual o futuro cronista, se todos os outros monumentos históricos fossem perdidos, poderia reescrever a história do nosso tempo completa e graficamente".

A ordem em que as estratégias retóricas da publicidade são apresentadas neste artigo segue, grosso modo, a dos momentos históricos em que tiveram maior destaque. Com efeito, a evolução da retórica publicitária tende a obedecer a uma determinada sequência, com o predomínio consecutivo das estratégias da imposição, da argumentação, da sedução e da cumplicidade. Essa sequência coincide com uma certa ordem lógica dos discursos na matriz lacaniana utilizada aqui como inspiração. As transformações na publicidade, incluindo rupturas, como a revolução criativa, são tributárias de alterações no tipo prevalente de retórica.

A sequência anteriormente delineada indica um deslocamento progressivo de foco do que se chama de "hard sell" para o que se chama de "soft sell", no jargão publicitário. Ou seja, 0 apelo de vendas explícito, sem rodeios, é substituído por mensagens mais sutis. Isso é potencializado por modificações de ênfase, seja do texto para a imagem, seja do produto para 0 consumidor e para a atmosfera que circunda 0 
consumo. Para isso, contribui 0 amadurecimento do público e sua familiarização com os códigos publicitários. Motivos técnicos incidem igualmente nesses desenvolvimentos: assim, a propensão à compressão temporal de comerciais de televisão, de um minuto para 30 ou 15 segundos, deixa menos tempo para a argumentação lógica e para a montagem de situações de sedução, enquanto a interatividade da internet favorece a cumplicidade.

A mudança na retórica predominante da publicidade nas últimas décadas articula-se ademais com fatores estruturais mais gerais. As estratégias retóricas da imposição, da argumentação e da sedução relacionam-se de algum modo com a sociedade disciplinar, ao passo que a estratégia da cumplicidade relaciona-se com a sociedade de controle. Essa passagem acompanha a do modelo de regulação fordista para 0 pós-fordista, do consumo de massa para o flexível, que torna mais maleável o laço entre a publicidade e 0 consumidor. Adicionalmente, como se discute em outro artigo (Castro, 2015), a cumplicidade com o consumidor está associada ao suposto empoderamento deste no âmbito da racionalidade neoliberal.

\section{Referências}

ADORNO, Theodor W. Ohne Leitbild. Parva Aesthetica. In: Gesammelte Schriften, Bd. 10:1. Frankfurt am Main: Suhrkamp, 2003. p. 289-453.

APPADURAI, Arjun. Introduction: commodities and the politics of value. In: APPADURAI, Arjun (ed.).

The social life of things: commodities in cultural perspective. Cambridge (UK): Cambridge University Press, 1986. p. 3-63.

CASTR0, Julio Cesar Lemes de. A publicidade contemporânea e o paradigma da perversão.

Comunicação, Mídia e Consumo, v. 11, nº 30, p. 181198, janeiro/abril de 2014.

0 consumidor como agente no neoliberalismo. Matrizes, v. 9, $\mathrm{n}^{0}$ 2, p. 273-288, julho/ dezembro de 2015.

. Aplicações da teoria lacaniana dos discursos na área de comunicação. Intercom - Revista

Brasileira de Ciências da Comunicação, v. 39, $\mathrm{n}^{0} 2$, p. 99-113, maio/agosto de 2016.

BARTHES, Roland. Mythologies. Paris: Seuil, 1970.

BELL, Daniel. The cultural contradictions of capitalism. New York: Basic Books, 1978.

BENJAMIN, Walter. Gesammelte Schriften, Bd. V. Frankfurt am Main: Suhrkamp, 1991.

BERNAYS, Edward L. Propaganda. New York: Horace Liveright, 1928.

DELEUZE, Gilles. Pourparlers: 1972-1990. Paris: Minuit, 2003.

DICHTER, Ernest. The strategy of desire. New Brunswick and London: Transaction, 2002.

DOUGLAS, Mary; ISHERW00D, Baron. The world of goods: towards an anthropology of consumption. London and New York: Routledge, 1996.

ELLUL, Jacques. Propagandes. Paris: Economica, 1990. FOUCAULT, Michel. Dits et écrits, II: 1976-1988. Paris: Gallimard, 2001.

FRANK, Thomas C. The conquest of cool: business culture, counterculture, and the rise of hip consumerism. Chicago and London: University of Chicago Press, 1997. 
FRIEDAN, Betty. The feminine mystique. New York: W. W. Norton, 1963.

GINZBURG, Carlo. "Your country needs you": a case study in political iconography. History Workshop Journal, n. 52, p. 1-22, Autumn 2001.

GRAHAM, Laurel D. Domesticating efficiency: Lillian Gilbreth's scientific management of homemakers, 19241930. Signs, v. 24, n. 3, p. 633-675, 1999.

HALL, S. Roland. Writing an advertisement. Boston, New York and Chicago: Houghton Mifflin, 1915.

KLEIN, Naomi. No logo: taking aim at the brand bullies. 3rd ed. New York: Picador, 2010.

LACAN, Jacques. Discours de Jacques Lacan à l'Université de Milan le 12 mai 1972. In: Lacan in Italia 1953-1978. En Italie Lacan. Milan: La Salamandra, 1978. p. 32-55.

Le séminaire, livre XVII: l'envers

de la psychanalyse. Paris: Seuil, 1991.

LAZARSFELD, Paul F;; BERELSON, Bernard; GAUDET, Hazel. The people's choice: how the voter makes up his mind in a presidential campaign. New York: Columbia University Press, 1944.

LEARS, T. J. Jackson. From salvation to selfrealization: advertising and the therapeutic roots of the consumer culture, 1880-1930. In: FOX, Richard Wightman; LEARS, T. J. Jackson (eds.). The culture of consumption: critical essays in American history 18801980. New York: Pantheon, 1983. p. 1-38.

LEWIS, E. St. Elmo. Financial advertising for commercial and savings banks, trust, title insurance, and safe deposit companies, investment houses. Indianapolis: Levey Brothers, 1908.

LINK, Henry C. The new psychology of selling and advertising. New York: Macmillan, 1932.

LIPPMANN, Walter. The phantom public: a sequel to "Public opinion". New York: Macmillan, 1927.
MANNONI, Octave. Clefs pour l'imaginaire ou l'Autre scène. Paris: Seuil, 1969.

OGILVY, David. Ogilvy on advertising. New York: Vintage, 1985.

PACKARD, Vance. The hidden persuaders. New York: Ig Publishing, 2007.

PECH, Thierry. La passion des sondages. In: GARCIN, Jérôme (ed.). Nouvelles mythologies. Paris: Seuil, 2007. p. 125-129.

PENDERGRAST, Mark. For God, country and CocaCola: the definitive history of the great American soft drink and the company that makes it. 3rd rev. and exp. ed. New York: Basic Books, 2013.

REEVES, Rosser. Reality in advertising. New York: Alfred A. Knopf, 1961.

SALECL, Renata. On anxiety. London and New York: Routledge, 2004.

THE NEW ADVERTISING. Harper's Weekly, v. 41, n. 2118, p. 744, Jul 24, 1897.

VEBLEN, Thorstein. The theory of the leisure class: an economic study of institutions. New York: B. W. Huebsch, 1918.

\section{WEBER, Max. Wirtschaft und Gesellschaft.}

Tübingen: J. C. B. Mohr, 1922. 


\begin{tabular}{|c|c|}
\hline $\begin{array}{l}\text { Advertising rhetorical } \\
\text { strategies: a proposal } \\
\text { for classificatory matrix }\end{array}$ & $\begin{array}{l}\text { Las estrategias retóricas } \\
\text { de la publicidad: una propuesta } \\
\text { de matriz clasificatoria }\end{array}$ \\
\hline $\begin{array}{l}\text { Abstract } \\
\text { It is proposed in this article a matrix to identify and } \\
\text { classify the most comprehensive rhetorical strategies } \\
\text { used historically by advertising. This is a work of } \\
\text { theoretical articulation, supported by bibliographical } \\
\text { research of interdisciplinary scope and illustrated } \\
\text { with examples from advertising practice. Inspired } \\
\text { by the Lacanian theory of discourses, the text takes } \\
\text { from each discourse its most characteristic trait as } \\
\text { the foundation of a particular rhetorical strategy: } \\
\text { imposition (master's discourse), argumentation } \\
\text { (discourse of university), seduction (discourse of } \\
\text { hysteria), and complicity (discourse of capitalism). } \\
\text { These strategies vary according to product, vehicle, } \\
\text { public and culture, and combine in different ways. } \\
\text { Over time, it can be seen grosso modo the successive } \\
\text { predominance of the various strategies. } \\
\text { Keywords } \\
\text { Advertising. Rhetoric. Discourses. }\end{array}$ & $\begin{array}{l}\text { Resumen } \\
\text { Se propone en este artículo una matriz para } \\
\text { identificar y clasificar las estrategias retóricas } \\
\text { más amplias utilizadas históricamente por la } \\
\text { publicidad. Se trata de un trabajo de articulación } \\
\text { teórica, apoyado en búsqueda bibliográfica de } \\
\text { ámbito interdisciplinario e ilustrado con ejemplos } \\
\text { de la práctica publicitaria. Inspirado por la teoría } \\
\text { lacaniana de los discursos, el texto toma a cada uno } \\
\text { de esos su aspecto más característico como la base } \\
\text { de una estrategia retórica particular: imposición } \\
\text { (discurso del señor), argumentación (discurso de } \\
\text { la universidad), seducción (discurso de la histeria) } \\
\text { y complicidad (discurso del capitalismo). Estas } \\
\text { estrategias varían según el producto, el vehículo, } \\
\text { el público y la cultura, y se combinan de diferentes } \\
\text { maneras. Con el tiempo, se puede ver grosso modo el } \\
\text { predominio sucesivo de las varias estrategias. } \\
\text { Palabras clave } \\
\text { Publicidad. Retórica. Discursos. }\end{array}$ \\
\hline
\end{tabular}




\section{Expediente}

A revista E-Compós é a publicação científica em formato eletrônico da Associação Nacional dos Programas de Pós-Graduação em Comunicação (Compós). Lançada em 2004, tem como principal finalidade difundir a produção acadêmica de pesquisadores da área de Comunicação, inseridos em instituições do Brasil e do exterior.

\section{E-COMPÓS I www.e-compos.org.br I E-ISSN 1808-2599}

Revista da Associação Nacional dos Programas de Pós-Graduação em Comunicação.

Brasília, v.19, n.3, set./dez. 2016.

A identificação das edições, a partir de 2008, passa a ser volume anual com três números.

Indexada por Latindex I www.latindex.unam.mx

\section{CONSELHO EDITORIAL}

Alexandre Farbiarz, Universidade Federal Fluminense, Brasil Alexandre Rocha da Silva, Universidade Federal do Rio Grande do Sul, Brasil Ana Carolina Escosteguy, Pontifícia Universidade Católica do Rio Grande do Sul, Brasil Ana Carolina Rocha Pessôa Temer, Universidade Federal de Goiás, Brasil Ana Regina Barros Rego Leal, Universidade Federal do Piauí, Brasil Andrea França, Pontifícia Universidade Católica do Rio de Janeiro, Brasil André Luiz Martins Lemos, Universidade Federal da Bahia, Brasil Antonio Carlos Hohlfeldt, Pontifícia Universidade Católica do Rio Grande do Sul, Brasil Arthur Ituassu, Pontifícia Universidade Católica do Rio de Janeiro, Brasil Álvaro Larangeira, Universidade Tuiuti do Paraná, Brasil Ângela Freire Prysthon, Universidade Federal de Pernambuco, Brasil César Geraldo Guimarães, Universidade Federal de Minas Gerais, Brasil Cláudio Novaes Pinto Coelho, Faculdade Cásper Líbero, Brasil Daisi Irmgard Vogel, Universidade Federal de Santa Catarina, Brasil Denize Correa Araujo, Universidade Tuiuti do Paraná, Brasil

Eduardo Antonio de Jesus, Pontifícia Universidade Católica de Minas Gerais, Brasil Daniela Zanetti, Universidade Federal do Espirito Santo, Brasil

Eduardo Vicente, Universidade de São Paulo, Brasil

Elizabeth Moraes Gonçalves, Universidade Metodista de São Paulo, Brasil Erick Felinto de Oliveira, Universidade do Estado do Rio de Janeiro, Brasil Francisco Elinaldo Teixeira, Universidade Estadual de Campinas, Brasil Francisco Paulo Jamil Almeida Marques, Universidade Federal do Paraná, Brasil Gabriela Reinaldo, Universidade Federal do Ceará, Brasil

Goiamérico Felício Carneiro Santos, Universidade Federal de Goiás, Brasil Gustavo Daudt Fischer, Universidade do Vale do Rio dos Sinos, Brasil Herom Vargas, Universidade Municipal de São Caetano do Sul, Brasil Itania Maria Mota Gomes, Universidade Federal da Bahia, Brasil Janice Caiafa, Universidade Federal do Rio de Janeiro, Brasil Jiani Adriana Bonin, Universidade do Vale do Rio dos Sinos, Brasil
José Afonso da Silva Junior, Universidade Federal de Pernambuco, Brasil José Luiz Aidar Prado, Pontifícia Universidade Católica de São Paulo, Brasil Juçara Gorski Brittes, Universidade Federal de Ouro Preto, Brasil Kati Caetano, Universidade Tuiuti do Paraná, Brasil Lilian Cristina Monteiro França, Universidade Federal de Sergipe, Brasil Liziane Soares Guazina, Universidade de Brasilia, Brasil Luíza Mônica Assis da Silva, Universidade de Caxias do Sul, Brasil Luciana Miranda Costa, Universidade Federal do Pará, Brasil Malena Segura Contrera, Universidade Paulista, Brasil Monica Martinez, Universidade de Sorocaba, Brasi Maria Ataide Malcher, Universidade Federal do Pará, Brasil Marcia Tondato, Escola Superior de Propaganda e Marketing, Brasil Marcel Vieira Barreto Silva, Universidade Federal da Paraíba, Brasil Maria Clotilde Perez Rodrigues, Universidade de São Paulo, Brasil Maria das Graças Pinto Coelho, Universidade Federal do Rio Grande do Norte, Brasil Mauricio Ribeiro da Silva, Universidade Paulista, Brasil

Mauro de Souza Ventura, Universidade Estadual Paulista, Brasil Márcio Souza Gonçalves, Universidade do Estado do Rio de Janeiro, Brasil Micael Maiolino Herschmann, Universidade Federal do Rio de Janeiro, Brasil Mirna Feitoza Pereira, Universidade Federal do Amazonas, Brasil Nísia Martins Rosario, Universidade Federal do Rio Grande do Sul, Brasil Potiguara Mendes Silveira Jr, Universidade Federal de Juiz de Fora, Brasil Regiane Regina Ribeiro, Universidade Federal do Paraná, Brasil Rogério Ferraraz, Universidade Anhembi Morumbi, Brasil Rose Melo Rocha, Escola Superior de Propaganda e Marketing, Brasil Rozinaldo Antonio Miani, Universidade Estadual de Londrina, Brasil Sérgio Luiz Gadini, Universidade Estadual de Ponta Grossa, Brasil Simone Maria Andrade Pereira de Sá, Universidade Federal Fluminense, Brasil Veneza Mayora Ronsini, Universidade Federal de Santa Maria, Brasil Walmir Albuquerque Barbosa, Universidade Federal do Amazonas, Brasil

\section{CONSELHO CIENTÍFICO}

Cristiane Freitas Guttreind, Pontifícia Universidade Católica do Rio Grande do Sul, Brasil Eduardo Morettin, Universidade de São Paulo, Brasil Felipe Costa Trotta, Universidade Federal Fluminense, Brasil Irene de Araújo Machado, Universidade de São Paulo, Brasil

\section{COMISSÃO EDITORIAL}

Eduardo Antonio de Jesus, Pontifícia Universidade Católica de Minas Gerais, Brasil Osmar Gonçalves dos Reis Filho, Universidade Federal do Ceará, Brasil

\section{CONSULTORES AD HOC}

Geane C. Alzamora, Universidade Federal de Minas Gerais, Brasil Teresinha Cruz Pires, Pontifícia Universidade Católica de Minas Gerais, Brasil

\section{EQUIPE TÉCNICA}

ASSISTENTE EDITORIAL Márcio Zanetti Negrini

REVISÃO DE TEXTOS Press Revisão

EDITORAÇÃO ELETRÔNICA Roka Estúdio

IMAGEM DE CAPA Silas de Paula

\section{COMPÓS I www.compos.org.br}

Associação Nacional dos Programas de Pós-Graduação em Comunicação

Presidente

Edson Fernando Dalmonte

Programa de Pós-Graduação em Comunicação

e Cultura Contemporânea - UFBA

edsondalmonte@uol.com.br

Vice-presidente

Cristiane Freitas Gutfreind

Programa de Pós-Graduação em Comunicação Social - PUC-RS cristianefreitas@pucrs.br

Secretário-Geral

Rogério Ferraraz

Programa de Pós-Graduação em Comunicação

Universidade Anhembi Morumbi

rogerioferraraz@anhembimorumbi.edu.br

CONTATO I revistaecompos@gmail.com 